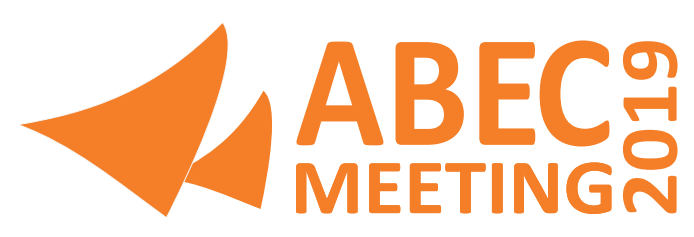

\title{
CONTRIBUIÇÃO DOS FATORES CRÍTICOS DE SUCESSO PARA OS PERIÓDI- COS CIENTÍFICOS
}

\author{
Contribution of critical success factors to scientific journals
}

\author{
Laodiceia Weersman \\ Kattiana Gomes
}

\section{COMO CITAR}

Weersman, Laodiceia; Gomes, Kattiana. Contribuição dos fatores críticos de sucesso para os periódicos científicos. In: ABEC Meeting, 2019, Fortaleza. Anais... São Paulo: Associação Brasileira de Editores Científicos, 2019. http://dx.doi.org/10.21452/abecmeeting.2019.216

\section{RESUMO}

As mudanças tecnológicas e nas economias têm impactado nos processos de gestão nos diversos ambientes organizacionais, como também no modus operandi de fazer e publicar a ciência. Nesta perspectiva, o objetivo deste artigo é identificar os Fatores Críticos de Sucesso (FCS) que contribuem para a otimização do Fluxo Editorial Científico. A metodologia utilizada apresentou uma abordagem quantitativa, de caráter descritivo com base em um survey disponibilizada nas redes sociais, mais especificamente, em grupos de facebook e whatsapp no qual participam pesquisadores e editores científicos, mediante questionário delineado com a escala Likert de cinco pontos e aplicado com a utilização da plataforma google forms. A amostra dar-se por sistema nomeado de bola de neve. A análise dar-se por estatística descritiva, mediante o emprego da média ponderada e a moda das respostas, bem como a construção do gráfico de radar compilando os resultados por proporcionar maior facilidade no trato de sua apresentação. Os principais resultados evidenciam que os FCS são: sistema de avaliação por pares, a qualidade editorial, a perenidade e o extrato na classificação do Qualis no qual o periódico se encontra. Esses fatores quando bem geridos viabilizam os periódicos, uma vez que estes necessitam cumprir com normas estabelecidas para que possam receber uma avaliação satisfatória quanto aos critérios de excelências e qualidade e tornarem-se um canal propício das publicações científicas.

\section{PALAVRAS-CHAVE}

Periódico Científico. Fluxo Editorial. Fatores Críticos de Sucesso. 


\section{ABSTRACT}

Technological and economical changes have impacted management processes in various organizational environments, as well as the modus operandi of making and publishing science. In this perspective, the objective of this paper is to identify the Critical Success Factors (CSF) that contribute to the optimization of the Scientific Editorial Flow. The methodology used is a quantitative, descriptive approach based on a survey available on social networks, more specifically in facebook and whatsapp groups in which participate researchers and scientific editors, applying a questionnaire that is delineated with the five-point Likert scale using the google forms platform. The sampling method is the so-called snowball sampling. The analysis is performed using descriptive statistics, like the weighted mean and mode of the answers, as well as the construction of a radar chart compiling the results to provide a better way to present them. The main results provide evidence that the CFS are: peer review system, editorial quality, perpetuity and the performance class in the Qualis Journal Ranking in which the journal is inserted. These factors, when well managed, make journals viable, as they need to comply with established standards to receive a satisfactory evaluation of the excellence and quality criteria and so can become a conducive channel for scientific publication.

\section{KEYWORDS}

Scientific Journal. Editorial flow. Critical Success Factors.

\section{INTRODUÇÃO}

As mudanças tanto econômicas e como tecnológicas estão alterando a forma de gerenciamento, em busca de obtenção de melhores resultados, frente aos desafios dos cenários dinâmicos. Novas ferramentas informatizadas têm sido desenvolvidas, alterando significativamente as formas tradicionais de atuação, mesmo em atividades tradicionais, como a pesquisa científica.

Destarte, com a evolução da web e de novas tecnologias que proporciona o desenvolvimento de outras formas de comunicação, os periódicos necessitam inovar e aprimorar os meios de publicação e divulgação da pesquisa científica, de modo que assegurem o compartilhamento do conhecimento e, conjuntamente, cumpram com os parâmetros essenciais de qualidade, periodicidade e visibilidade, propiciando, assim, o seu reconhecimento perante a comunidade acadêmica.

Sendo assim, este estudo visa responder a seguinte questão orientadora: Quais os Fatores Críticos de Sucesso (FCS) que contribuem para a otimização do fluxo editorial científico? Neste sentido, toma-se como pressuposto básico que os FCS podem relacionar-se com os critérios de um periódico, bem como com suas com as áreas de desenvolvimento. Assim, justifica-se estudo pela relevância que a pesquisa trará aos periódicos na celeridade de suas publicações, ao identificar os Fatores Críticos de Sucesso, para a obtenção de maior eficácia nas publicações.

A relevância da pesquisa decorre ainda diante do posicionamento da produção científica no Brasil ainda requerer de melhores padrões competitivos internacionais, pois o país apresenta-se em $12^{\circ}$ lugar no ranking mundial da produção científica, totalizando 53 mil artigos em 2016. Um crescimento significativo de $89 \%$ na quantidade de artigos publicados, no entanto, é despropor- 
cional a disparidade perante as economias emergentes. (JORNAL DA CIÊNCIA, 2018).

Ademais, a estrutura deste artigo contempla, além dessa introdução, o referencial teórico que embasa a pesquisa, a metodologia que estabelece o método de condução da pesquisa. Posteriormente, tem-se a análise dos resultados que viabiliza a discursão dos dados encontrados frente a literatura abordada e, por fim, é tecida a conclusão, a qual prioriza pelo fechamento da ideia do que foi pesquisado com a questão orientadora.

\section{CARACTERIZAÇÃO E CRITÉRIOS DO PERIÓDICO}

Na segunda metade do século $X X$, as inovações nas áreas da tecnologia de informação e comunicação, iniciam de maneira acelerada um desenvolvimento, que modifica em diversos aspectos a forma de fazer a produção científica, surgindo os periódicos eletrônicos e se sobrepondo aos impressos, mediante suas características que proporcionam uma maior difusão, diminuição de custos e celeridade em suas edições (PEREIRA; LOBÃO; LUCAS, 2017).

Segundo a ANPAD (2010), na ótica de autores e de suas instituições, o periódico acadêmico tem, inicialmente, como principal função a divulgação dos resultados de pesquisas da forma mais abrangente possível. Em consonância com essa perspectiva, os autores Job, Mattos e Ferreira (2013) afirmam que uma revista científica tem como seu core competence transmitir a informação, objetivando alcançar uma significativa audiência com seu público leitor, o qual é formado por uma comunidade científica profissionalmente especializada.

Segundo Weersma, Shintaku e Coelho (2018), a questão da legitimação do conteúdo, quanto aos periódicos científicos, ocorre por meio da avaliação pelos pares, garantindo os parâmetros de qualidade. Uma vez que a qualidade das produções científicas e a periodicidade são requisitos exigidos pelas bases de indexação, tais características possibilitam que as revistas obtenham a visibilidade e alcancem a internacionalização do seu periódico.

Contudo, à editoria incumbe o gerenciamento do periódico, cabendo-lhe as decisões finais quanto aos critérios de avaliação dos artigos ao serem selecionados para publicação. Tendo, o editor, a missão de gerir a revista e a intermediar a comunicação entre autores e avaliadores, certificando-se de que o processo editorial execute sua função de maneira transparente e com isonomia, a qual é produzir um conhecimento consolidado, sério e democraticamente orientado (VASCONCELLOS, 2017).

No entanto, para que haja uma viabilização para o alcance desses objetivos, os autores Sandes-Guimarães e Diniz (2014) afirmam que o gerenciamento do fluxo editorial deve ocorrer mediante a execução de três tipos de gestão: a científica, a administrativa e a financeira. As quais irão apresentar indicadores que permitirão a mensuração do controle nos processos, destacando assim os fatores críticos de sucesso de um periódico científico.

\section{FATORES CRIITICOS DE SUCESSO (FCS)}

Visando a administração dos recursos necessários no processo do fluxo editorial e na obtenção do êxito nos resultados, que é garantir a divulgação das publicações do periódico, os autores Spudeit, Werlang e Presser (2012) enumeraram um sistema de indicadores que possibilitará 
compreender as ações a ser empreendidas para atingir tal finalidade.

Quadro 1. Proposição de um sistema de indicadores do fluxo editorial do Periódico Científico

\begin{tabular}{|c|c|}
\hline CRITÉRIOS & INDICADORES \\
\hline Classificação Qualis & - Estrato de classificação do periódico no triênio. \\
\hline $\begin{array}{l}\text { Adequação técnico- normativa do } \\
\text { periódico. }\end{array}$ & $\begin{array}{l}\text { - Proporção de fascículos atendendo às normas e especificações } \\
\text { estabelecidas no regulamento do periódico. }\end{array}$ \\
\hline $\begin{array}{l}\text { Qualidade editorial: aderência dos } \\
\text { temas das seções à área temática } \\
\text { do periódico, preservando a } \\
\text { missão, foco e escopo do } \\
\text { periódico; coerência das seções } \\
\text { do periódico } \\
\text { com a linha editorial. }\end{array}$ & $\begin{array}{l}\text { - Proporção de seções dos fascículos atendendo à finalidade do } \\
\text { periódico, enunciada e sintetizada na sua missão, foco e escopo- } \\
\text { Proporção de seções (artigos de pesquisa, originais e inéditos, } \\
\text { resenhas, relatos de pesquisa etc.), por volume. }\end{array}$ \\
\hline Avaliação pelos pares & $\begin{array}{c}\text { - Composição do quadro de avaliadores ad hoc / Percentual de seus } \\
\text { integrantes vinculados a instituições externas, com diferentes } \\
\text { vinculações institucionais de, no mínimo, um por região / Percentual } \\
\text { de representatividade institucional entre os avaliadores ad hoc / } \\
\text { Quantidade de artigos avaliados por avaliador no período de um ano / } \\
\text { Quantidade de avaliadores ad hoc para cada seção do periódico / } \\
\text { Percentual de novos avaliadores cadastrados em cada período de um } \\
\text { ano. }\end{array}$ \\
\hline $\begin{array}{l}\text { Conselho Editorial e Conselho } \\
\text { Científico }\end{array}$ & $\begin{array}{l}\text { - Composição do conselho editorial e do conselho científico / } \\
\text { Percentual de seus integrantes vinculados a instituições externas do } \\
\text { Brasil / Percentual de representantes de instituições estrangeiras / } \\
\text { Percentual de unidades da federação representadas no conselho. }\end{array}$ \\
\hline Autores & $\begin{array}{c}\text { - Percentual de artigos de autores filiados a instituições estrangeiras / } \\
\text { Percentual de artigos de autores filiados a instituições externas (não } \\
\text { incluídos os que tenham autoria estrangeira) / Percentual de autores } \\
\text { com titulação de doutor, mestre, especialistas e discentes (graduação } \\
\text { e pós-graduação) / Percentual de autores vinculados à instituição } \\
\text { patrocinadora do periódico. }\end{array}$ \\
\hline Periodicidade & - Proporção de edições lançadas na data prevista no regulamento. \\
\hline Regularidade das Edições & - Intervalo médio entre submissão e aceite. \\
\hline Qualidade científica & $\begin{array}{l}\text { - Percentual dos trabalhos avaliados e aprovados para publicação, } \\
\text { com ou sem restrições. }\end{array}$ \\
\hline Perenidade & $\begin{array}{l}\text { - Tempo de publicação, para medir a continuidade da publicação } \\
\text { científica. }\end{array}$ \\
\hline Visibilidade & $\begin{array}{l}\text { - Índice de acessos no ano/ Índice de cadastro de novos leitores no } \\
\text { ano/ Número de indexações nos repositórios e/ou catálogos de } \\
\text { bibliotecas no ano / Número de indexações em bases de dados } \\
\text { nacionais e estrangeiras, recomendadas pela área / Índice de } \\
\text { visibilidade em sítios de busca (Page Rank) entre as edições / Índice } \\
\text { de fator de impacto no triênio. }\end{array}$ \\
\hline
\end{tabular}

Fonte: Spudeit, Werlang e Presser (2012, p. 112). 


\section{METODOLOGIA}

A pesquisa desenvolvida neste artigo caracteriza-se quanto à abordagem como quantitativa, uma vez que esse tipo de pesquisa tem como foco descrever, explicar e prever, ou seja, fazer uma mensuração de algo. 0 envolvimento do pesquisador é controlado e limitado, para evitar viés, visto que se tem como objetivo construir e testar teorias, por meio de uma amostragem probabilística (COOPER; SCHINDLER, 2011).

Posiciona-se como descritiva, a qual segundo Mascarenhas (2012), tem como objetivo relatar as características de uma população ou fenômeno e distinguir quais as relações existentes entre as variáveis analisadas. A coleta da base de dados se dá com base em survey e a amostra por "bola de neve", e a aplicação do questionário dar-se mediante a utilização da plataforma Google Forms e disponibilizada nas redes sociais, mais especificamente, em grupos de facebook e whatsapp no qual participam pesquisadores e editores científicos em que estão inseridos uma quantidade de 2.000 pesquisadores.

Esse tipo de amostragem viabiliza o pesquisador estudar grupos específicos e de difícil acesso. Segundo Vinuto (2014) a amostragem em bola de neve apresenta-se como um processo em que o investigador busca nas redes sociais dos entrevistados informações constantes, para que dessa forma possa proporcionar um maior número de contatos potenciais, sendo o estudo finalizado a partir do critério de ponto de saturação. O questionário utiliza da escala proposta por Spudeit, Werlang e Presser (2012, p. 112). E está estruturado utilizando-se da escala de Likert de cinco pontos. A análise dar-se mediante estatística descritiva, com o emprego da média ponderada e da moda das respostas, bem como a construção do gráfico de teia compilando os resultados por proporcionar maior facilidade no trato de sua apresentação.

\section{ANÁLISE DOS RESULTADOS}

\subsection{Critérios a luz dos periódicos científicos}

A análise foi fundamentada na utilização da escala Likert, a qual buscou identificar os elementos mais frequentes e utilizados pelos periódicos, através da moda e da média ponderada, de modo que garantisse em atender os principais atributos como qualidade, periodicidade e visibilidade.

Os aspectos abordados na pesquisa para avaliar o grau de utilização dos critérios pelos periódicos em suas edições são: Classificação Qualis, Adequação técnica-normativa, Qualidade editorial, Avaliação por pares, Conselho editorial e Científico, Autores, Periodicidade, Regularidade das edições, Qualidade Científica, Perenidade e Visibilidade. O Gráfico 01 apresenta os critérios mais utilizados. 
Gráfico 1. Critérios dos Periódicos Científicos

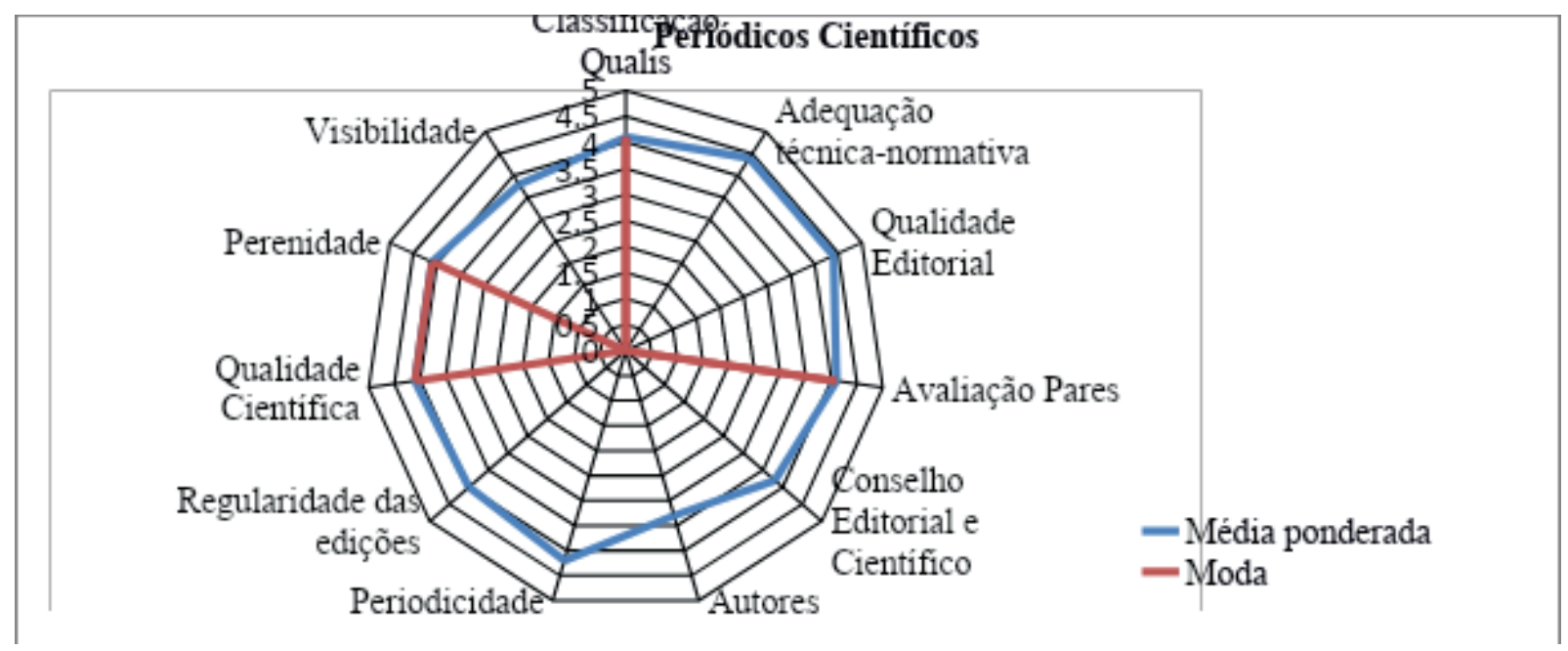

Fonte: Dados da pesquisa (218)

Os parâmetros que se destacaram como os mais utilizados pelos periódicos, obtendo a maior média ponderada foram: Adequação técnica-normativa e Qualidade Editorial atingindo o valor de 4,4 na média. Classificação Qualis, Avaliação por Pares, Qualidade Científica e Perenidade, todas alcançando o valor de 4,1. No entanto, os eventos que se apresentaram como os mais frequentes, identificados pela moda foram: sistema de avaliação por pares, a qualidade editorial, a perenidade e o extrato na classificação do Qualis no qual o periódico se encontra. Esses fatores mais frequentes quando bem geridos viabilizam os periódicos, uma vez que estes necessitam cumprir com normas estabelecidas para que possam receber uma avaliação satisfatória quanto aos critérios de excelências e qualidade e tornarem-se um canal propício das publicações científicas.

\section{CONCLUSÃO}

A pesquisa desenvolvida neste artigo caracteriza-se quanto à abordagem como quantitativa, uma vez que esse tipo de pesquisa tem como foco descrever, explicar e prever, ou seja, fazer uma mensuração de algo. O envolvimento do pesquisador é controlado e limitado, para evitar viés, visto que se tem como objetivo construir e testar teorias, por meio de uma amostragem probabilística (COOPER; SCHINDLER, 2011).

Posiciona-se como descritiva, a qual segundo Mascarenhas (2012), tem como objetivo relatar as características de uma população ou fenômeno e distinguir quais as relações existentes entre as variáveis analisadas. A coleta da base de dados se dá com base em survey e a amostra por "bola de neve", e a aplicação do questionário dar-se mediante a utilização da plataforma Google Forms e disponibilizada nas redes sociais, mais especificamente, em grupos de facebook e whatsapp no qual participam pesquisadores e editores científicos em que estão inseridos uma quantidade de 2.000 pesquisadores.

Esse tipo de amostragem viabiliza o pesquisador estudar grupos específicos e de difícil acesso. Segundo Vinuto (2014) a amostragem em bola de neve apresenta-se como um processo em que o investigador busca nas redes sociais dos entrevistados informações constantes, para 
que dessa forma possa proporcionar um maior número de contatos potenciais, sendo o estudo finalizado a partir do critério de ponto de saturação. O questionário utiliza da escala proposta por Spudeit, Werlang e Presser (2012, p. 112). E está estruturado utilizando-se da escala de Likert de cinco pontos. A análise dar-se mediante estatística descritiva, com o emprego da média ponderada e da moda das respostas, bem como a construção do gráfico de teia compilando os resultados por proporcionar maior facilidade no trato de sua apresentação.

\section{REFERÊNCIAS}

ASSOCIAÇÃO NACIONAL DE PÓS-GRADUAÇÃO E PESQUISA EM ADMINISTRAÇÃO (ANPAD). Boas práticas da publicação científica: um manual para autores, revisores, editores e integrantes de corpos editoriais. 2010. Disponível em: <https://www.mackenzie.br/fileadmin/ARQUI$\mathrm{V} \quad \mathrm{O} \quad \mathrm{S} / \mathrm{P} \quad \mathrm{u} \quad \mathrm{b} / \mathrm{i} \quad \mathrm{c} / \mathrm{t} \quad \mathrm{o} \quad \mathrm{p} / \mathrm{m}$ i dias_noticias/editora/old/Editora/Revista_Administracao/Boas_Praticas.pdf>. Acesso em: 25 nov. 2018.

COOPER, D. R.; SCHINDLER, P. S. Métodos de pesquisa em administração.10. ed. Porto Alegre: Bookman, 2011.

JOB, Ivone; MATTOS, Ana Maria; FERREIRA, Ana Gabriela Clipes. Análise do acesso aos artigos de uma revista eletrônica através dos logs. Revista brasileira de ciências do esporte, Campinas, SP. vol. 35, n. 2,(abr./jun. 2013), p. 359-371, 2013. Disponível em: <https://www.lume.ufrgs.br/handle/10183/150378>. Acesso em: 06 nov. 2018.

KLEBIS, D. China é o país que produz mais artigos científicos no mundo. Brasil é o $12^{\circ}$. Jornal da Ciência, Publicação da Sociedade Brasileira para o Progresso da Ciência (SBPC), São Paulo, 16 jan. 2018. Disponível em: <http://www.jornal daciencia.org.br/china-e-o-pais-que-produz-mais-artigos-cientificos-no-mundo-brasil-e-o-12o/>. Acesso e m: 15 out. 2018.

MASCARENHAS, S. A. Metodologia científica. São Paulo: Pearson, 2012.

PEREIRA, D. Borges.; LOBÃO, I. de S. L.; LUCAS, E. R de O. Internacionalização de periódicos científicos brasileiros: exigências requeridas. RBBD: Revista Brasileira de Bibliote conomia e Docu mentação, v. 13, p. 2300-2313, 2017. Disponível em: <https://febab.Emnuvens.com.br/rbbd/article/view/865/ 940>. Acesso em: 20 nov. 2018.

SANDES-GUIMARÃES, L. V. de; DINIZ, E. H. Gestão de periódicos científicos: estudo de casos em revistas da área de Administração. R. Adm., São Paulo, v.49, n.3, p.449-461, jul./ago./set. 2014. Disponível em: <http://www. scielo.br/pdf/rausp/v49n3/a02v49n3.pdf>. Acesso em: 22 out. 2018. DOl:10.5700/rausp 1160

SPUDEIT, D.; WERLANG, E.; PRESSER, N. H. Indicadores de gestão do fluxo editorial dos periódicos científicos: uma reflexão teórico-metodológica. Encontros Bibli: revista eletrônica de biblioteconomia e ciência da informação, v. 17, n. esp. 2 - III SBCC, p.102-117, 2012. DOI: https://doi.org/10.5007/1518-2924.2012v17nesp2p102. Disponível em: <https://periodicos.ufsc.br/index.php/eb/article/view/27416>. Acesso em: 21 nov. 2018.

VASCONCELLOS, V. G. de. Editorial: A função do periódico científico e do editor para a produção 
do conhecimento no Direito e nas ciências criminais. Revista Brasileira de Direito Processual Penal, Porto Alegre, vol. 3, n. 1, p. 9-17, jan./abr. 2017. Disponível em: <http://www.ibraspp.com.br/revista/index.php/ RBDPP/article/view/34>. Acesso em: 13 nov. 2018. DOI: https://doi .org/10.22197/rbdpp.v3i1.34

VINUTO, J. A amostragem em bola de neve na pesquisa qualitativa: um debate em aberto. Temáticas, Campinas. n. 44, p. 203-220, 2014. Disponível em:<https://www.ifch. unicamp.br/ojs/index.php/tematicas/article/view/2144>. Acesso em: 18 dez. 2018.

WEERSMA, L. A; SHINTAKU, M.; COELHO, A. F. Compartilhamento de conhecimento: um olhar a partir das práticas de gestão da Revista Gestão em Análise (ReGeA). In: ABEC MEETING, 2, 2018, São Paulo. Anais...São Paulo: Associação Brasileira de Editores Científicos, 2018. p. 1-9. Disponível em: <http://ocs.abecbrasil.org.br/index. php/abec-meeting/abec-mee ting-2018/paper/viewFile/188/185>. Acesso em: 02 dez. 2018. Dol:http://dx.doi.org/10.2 1452/abecmeeting .2018 .188 